OPEN ACCESS

Edited by:

Jing-Yan Han,

Peking University, China

Reviewed by:

Ying Wang,

University of Macau, China

Hubiao Chen,

Hong Kong Baptist University,

Hong Kong

*Correspondence:

Kelvin Chan

k.k.chan@limu.ac.uk

Tina TX Dong

botina@ust.hk

${ }^{\dagger}$ These authors have contributed equally to this work

Specialty section:

This article was submitted to

Ethnopharmacology,

a section of the journal

Frontiers in Pharmacology

Received: 09 April 2019 Accepted: 29 November 2019

Published: 14 January 2020

Citation:

Gong G, Huang J, Yang Y, Qi B, Han G, Zheng Y, He H, Chan K, Tsim KWK and Dong TTX (2020) Saussureae Involucratae Herba

(Snow Lotus): Review of

Chemical Compositions and

Pharmacological Properties.

Front. Pharmacol. 10:1549. doi: 10.3389/fphar.2019.01549

\section{Saussureae Involucratae Herba (Snow Lotus): Review of Chemical Compositions and Pharmacological Properties}

\author{
Guowei Gong ${ }^{1 \dagger}$, Jing Huang ${ }^{2 \dagger}$, Yang Yang ${ }^{1}$, Baohui $\mathbf{Q i}^{1}$, Guangyi Han ${ }^{3}$, Yuzhong Zheng ${ }^{4}$, \\ Huan $\mathrm{He}^{1}$, Kelvin Chan ${ }^{5 *}$, Karl WK Tsim ${ }^{6,7}$ and Tina TX Dong ${ }^{6,7 *}$ \\ ${ }^{1}$ Department of Biological Engineering, Zunyi Medical University, Zhuhai, China, ${ }^{2}$ College of Environmental and Biological \\ Engineering, Putian University, Putian, China, ${ }^{3}$ Gansu Institute for Drug Control, Lanzhou, China, ${ }^{4}$ Department of Biology, \\ Hanshan Normal University, Chaozhou, China, ${ }^{5}$ School of Pharmacy \& Biomolecular Sciences, Liverpool John Moores \\ University, Liverpool, United Kingdom, 6 Shenzhen Key Laboratory of Edible and Medicinal Bioresources, HKUST Shenzhen \\ Research Institute, Shenzhen, China, ${ }^{7}$ Division of Life Science and Center for Chinese Medicine, The Hong Kong University \\ of Science and Technology, Hong Kong, Hong Kong
}

Saussureae Involucratae Herba is the dried ground part of Saussurea involucrata (Kar. et Kir.) Sch.-Bip, which is also named as "Snow lotus" and being used in traditional Uyghur and/or Chinese medicine. This rare herb can be found at 4,000 m elevation in western part of Tianshan Mountain, Xinjiang China. According to China Pharmacopoeia (2015), the major pharmaceutical values of "Snow lotus" (Xuě liánhuā in Chinese) are alleviating rheumatoid arthritis, accelerating blood circulation and mitigating other "cold" syndromes. Traditionally, the clinical application of "Snow lotus" includes the treatments in inflammation-associated disorder, blood circulation acceleration and heat and dampness elimination. Recent studies suggested that "Snow lotus" possessed therapeutic effects associating with anti-cancer, anti-oxidation, adipogenesis suppression and neuroprotection activities, which were proposed to be related with its bioactive constitutes, i.e. acacetin, hispidulin, and rutin. In the present review, we aim to summarize pharmacological effects and underlying cell signaling pathways of "Snow lotus" in treating various medical problems.

Keywords: Saussureae Involucratae Herba, traditional Chinese medicine, traditional Uyghur medicine, herbal medicine, Snow lotus

\section{INTRODUCTION}

The history of Traditional Uyghur medicine (TUM) spans over 2,500 years and is still being practiced today (Upur et al., 2011). Ghazi Bay recorded fennel, senna, salt and other 312 types of TUM herbs, as well as its therapeutic functions, in the book of "Ghazi Bay medicinal book", written in about 400 B.C. (Yishakejiang et al., 2005). The predominant concept of TUM is based on four unique elements of air, fire, water and soil, and each element is corresponding to specific humor, i.e. "phlegm", "blood", "yellow bile" and "black bile" (Shahabi et al., 2008). Uygur doctors believe that the occurrence of disease has close relationship with the destruction of temperament balance, which 
results in abnormal body fluid disequilibrium. The mainstay of health is to keep right ratio and precise balance of humors based on their quality and quantity. Therefore, adjusting and balancing body fluids are the fundamental principle for disorder treatments according to the TUM theory. Indeed, traditional Chinese medicine (TCM) and TUM share abundant similarities, and the major responsibilities of TUM and/or TCM are modulating health conditions, promoting health and having therapeutic strategies for specific diseases or symptom treatments. Nowadays, traditional medicine is often referring to complementary or alternative medicine. In developing countries, e.g. Asian and African, up to $80 \%$ of the population consumes herbal decoction in meeting the primary health care needs. A massive of ancient literatures, including book and pharmacopoeia, have recorded the existence of TCM and/or TUM prescriptions and their beneficial functions, disease preventions and clinical applications (Packer et al., 2004). Nevertheless, the metabolites, pharmaceutical values and action mechanisms of these TCM and/or TUM in modulating human health are still behind veil. This review provides some detailed information and pharmaceutical values of TUM and/or TCM herbal materials in general, using "Snow lotus" as an example.

According to the China Pharmacopoeia (2015), "Snow lotus" is the dried ground part of Saussurea involucrata (Kar. et Kir.) Sch.-Bip (Figure 1), which is being used for inflammationassociated disorder treatments, such as rheumatoid arthritis, cancer, modulating lipid metabolism, and improving

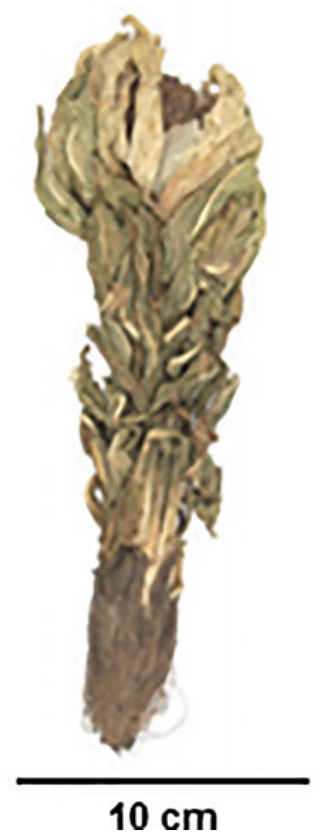

FIGURE 1 | The pictures of Snow lotus. Saussureae Involucratae Herba is described in the HKCMMS Volume 8. http://www.cmd.gov.hk/hkcmms/vol8/ pdf_e/Saussureae_Involucratae_Herba_v8_e.pdf. gynecological and reproductive problem, enhancing blood circulation and mitigation of other "cold" syndrome (Chik et al., 2015). The incidences of rheumatoid arthritis, gastric cancer and hepatic cancer are much less in Uygur population, as compared to other parts of China, probably have a close relationship with the common consumption of "Snow lotus" in Xinjiang area (Byambaragchaa et al., 2013; Yu et al., 2013; Chik et al., 2015; Wang et al., 2016). According to China Pharmacopeia (2015), the primary pharmaceutical values of "Snow lotus" is maintaining body homeostasis. Figure 2 summarizes the possible functions of "Snow lotus". The major bioactive components exhibited the clinical functions were reported to be acacetin, hispidulin and rutin (Chik et al., 2015). The structures of these chemicals are presently shown in Figure 3. Most of the "Snow lotus"-concentrated herbal decoctions are capable of mitigating "cold" syndromes or diseases both in male and female. This materia medica is one of the major ingredients found within "Snow lotus" capsule being sold in China, which is aiming for dysmenorrhoea treatment. Moreover, the water decoction having "Snow lotus", Lycii fructus and Angelica sinensis Radix could promote the secretion of androgen, to enhance the sexual function for male patients, which therefore has been used for infertility treatment (Zhao, 1963).

\section{BOTANICAL CLASSIFICATION}

"Snow lotus" is a dicotyledonous plant, classified under Compositae. The commonly found "Snow lotus" is clustered into subgenus of Amphilaena and Eriocovgne. The subgenus of Amphilaena contains S. involucrata, S. globosa, S. wettsteiniana, S. polycolea, S. uniflora, S. velutina, S. phaeantha, S. orgaadayi, S. tangutica, S. bracteata, S. erubescens, S. nigrescens, S. iodostegia, S. glandulosissima, and S. sikkimensi (Chen et al., 2019). The subgenus of Eriocovgne includes S. aster, S. glacialis, $S$. gnaphaloides, S. laniceps and S. medusa (Zhai et al., 2009). However, S. involucrata, S. laniceps, and S. medusa are the most commonly used species in clinical applications (Yi et al., 2010).

The morphological features of S. involucrata show similarities with S. laniceps and S. medusa (Chen et al., 2014a). The microscopic characteristics, as determined by scanning electron microscopy (SEM), of these Saussurea species had been reported and identified: the pollen grains were the indicative markers showing their distinctive characteristics. The pollen grains of $S$. laniceps was sub-rounded, light yellow, covered with perforate and verruca warts. However, the pollen of $S$. medusa was bigger, and the outer surface was sculptured with dense spinules. $S$. involucrata had yellow pollen and wart on outer surface (Chen et al., 2014a). Recently, a new species of "Snow lotus", named as $S$. bogedaensis, has been explored and reported in the eastern part of Tianshan Mountain (Chen and Wang, 2018). The genetic analysis showed that $S$. bogedaensis and $S$. involucrata had a close relationship, which might suggest that these two plants are deriving from a common ancestor (Chen and Wang, 2018). Moreover, S. bogedaensis shares similar pharmaceutical values 


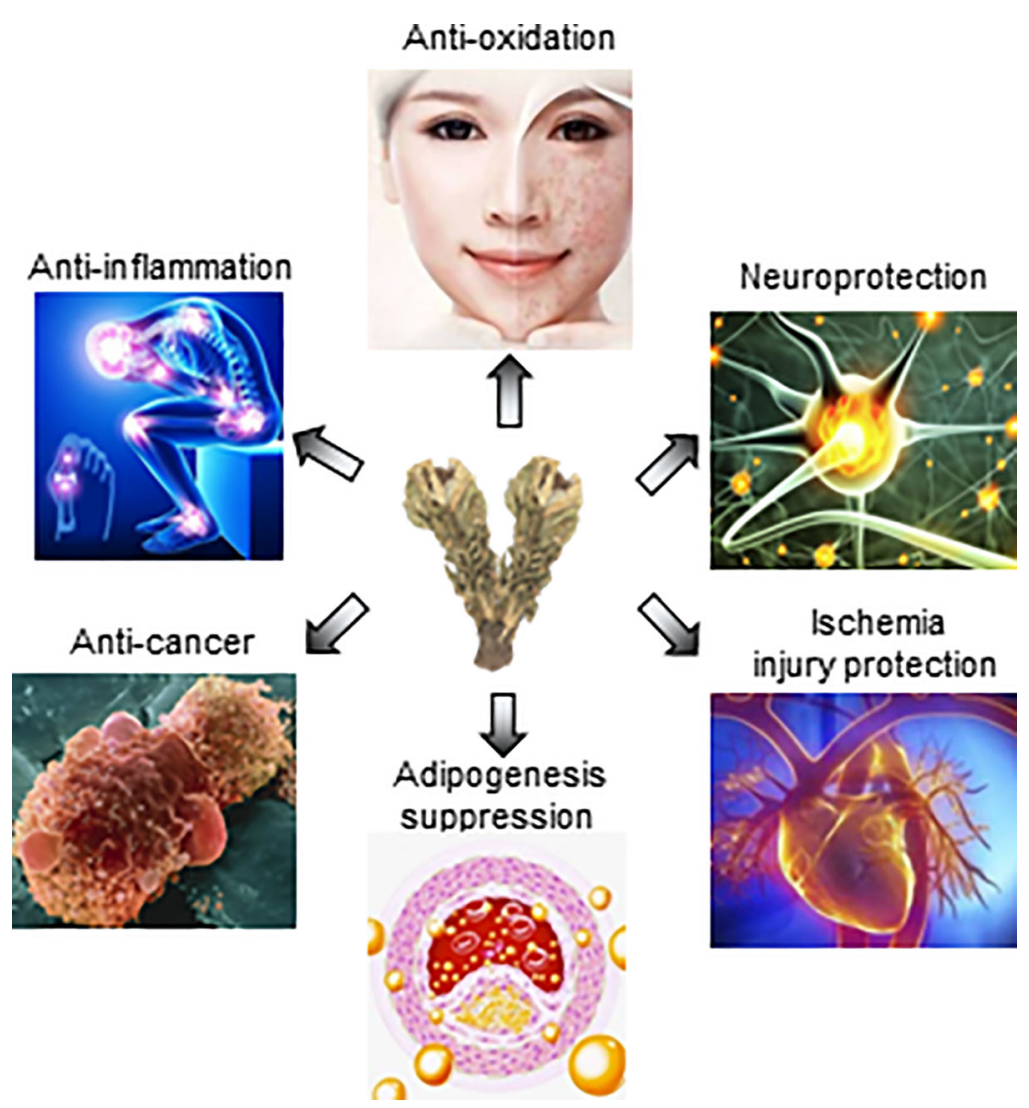

FIGURE 2 | The pharmaceutical values of Snow lotus. Saussureae Involucratae Herba possesses anti-oxidative functions, neuroprotective effects, anti-inflammatoryinduced diseases, anti-cancer, anti-obesity and ischemia injury protective pharmaceutical values.

\section{Acacetin}<smiles>COc1ccc(-c2cc(=O)c3c(O)cc(O)cc3o2)cc1</smiles>

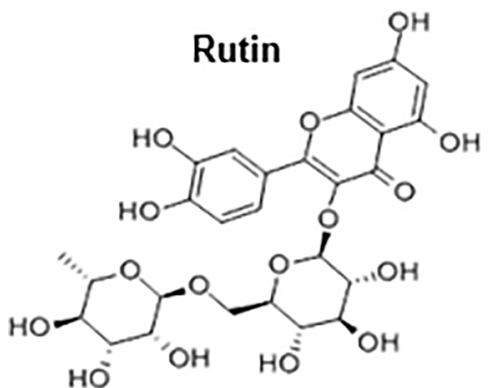

Hispidulin<smiles>COc1c(O)cc2oc(-c3ccc(O)cc3)cc(=O)c2c1O</smiles>

\section{Chlorogenic acid}<smiles>O=C(/C=C/c1ccc(O)c(O)c1)OC1CC(O)(C(=O)O)C[C@H](O)[C@H]1O</smiles>

FIGURE 3 | Chemical structures of major bioactive components isolated from Snow lotus. The chemical structures of acacetin, hispidulin, rutin and chlorogenic acid are shown here. 
with $S$. involucrate; hence, $S$. bogedaensis could act as an alternative to $S$. involucrata in clinical applications. Yi et al., 2010 conducted systematic experiments to demonstrate that $S$. laniceps was the most potent Saussurea species as the source of TCM, instead of S. involucrata or S. medusa.

\section{BIOSYNTHESIS OF SECONDARY METABOLITES}

The full-length gene encoding flavonoid-3-O-glucosyltransferase (3GT) (GenBank Accession No. JN092127), cloned from S. involucrata, was isolated and employed to search for the biosynthesis of plant secondary metabolites (Figure 4). The transcripts of 3GT members were detected massively in leaves and callus of $S$. involucrata, and which were able to catalyze the secondary glycosylation products by transferring activated sugar donors to acceptors. The $3 \mathrm{GT}$ gene of $S$. involucrata was constructed under the control of a cauliflower mosaic virus (CaMV) $35 \mathrm{~S}$ promoter, and then the homologous transformation was done by an agrobacterium rihizogenesmediated transformation system (Figure 4) (Tang et al., 2012). Thus, a transgenic S. involucrata having over expression of 3GT gene was generated. Two major transcriptional factors, i.e. anthocyanin pigment 1 (PAP1) and leaf color (Lc), involved in the phenylpropanoid pathways are proposed to contribute regulatory functions of the biosynthetic pathways (Qiu et al., 2013). In the genetic modified plant, S. involucrata, the over expressed PAP1 and Lc were able to accumulate purple pigments by the massive aggregation of anthocyanin (Qiu et al., 2013). In parallel, the increased augmentations of chlorogenic acid, syringin, cyanrine and rutin in the transgenic herbal material were able to increase its anti-oxidative functions, as measured by ABTS (2,2'-azinobis-3-ethylbenzotiazo-line-6-sulfonic acid) and FRAP (ferric reducing anti-oxidant power) (Figure 5) (Qiu et al., 2010).

\section{FUNGUS AND HOST PLANT}

Fungal growth on S. involucrata has been reported to play unique roles. Endophytic fungi, responsible for species diversity and keeping the host fitness, were isolated and identified by morphological and molecular methods from S. involucrata. The isolated fungi are classified into 14 taxa, and most of them are belonging to Cylindrocarpon sp. (Lv et al., 2010). Some of $S$. involucrata plants contain dark pigment that is named as dark septate endophytic (DSE) fungus (Lv et al., 2010). The most predominant DSE fungus was DSE-37, as determined by the DNA fragment of internal transcribed spacer regions. The results indicated that DSE-37 was congeneric to Mycocentrospora (Wu et al., 2010). After over one-month cultivation of S. involucrata in the present of DSE-37, fungal hyphae were branched and twisted together and finally formed "hyphae nets" in epidermal layers, which was proposed to be the positive effect of DSE-37 on the root development. Besides, the content of rutin was much concentrated in DSE-37 positive S. involucrata plants as compared to the control, indicating DSE-37 was one of

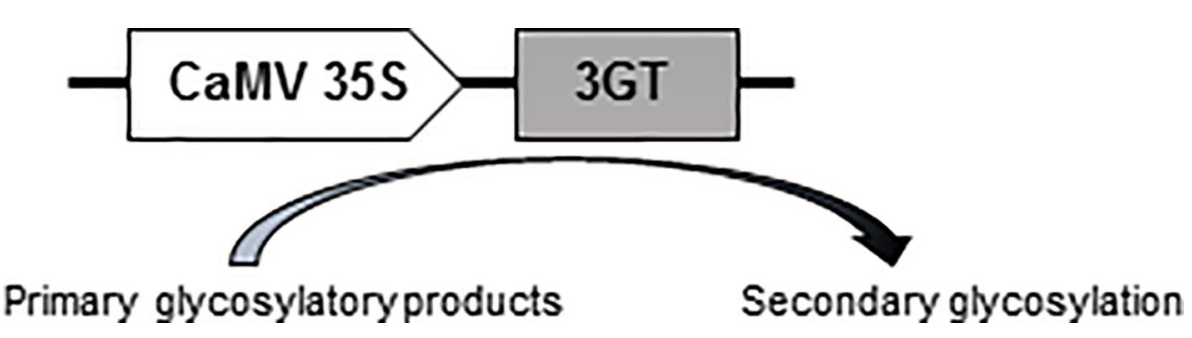

FIGURE 4 | Flow chart of secondary metabolites. The employment of 3GT was used in S. involucrata to catalyze the formation of primary glycosylatory metabolites.

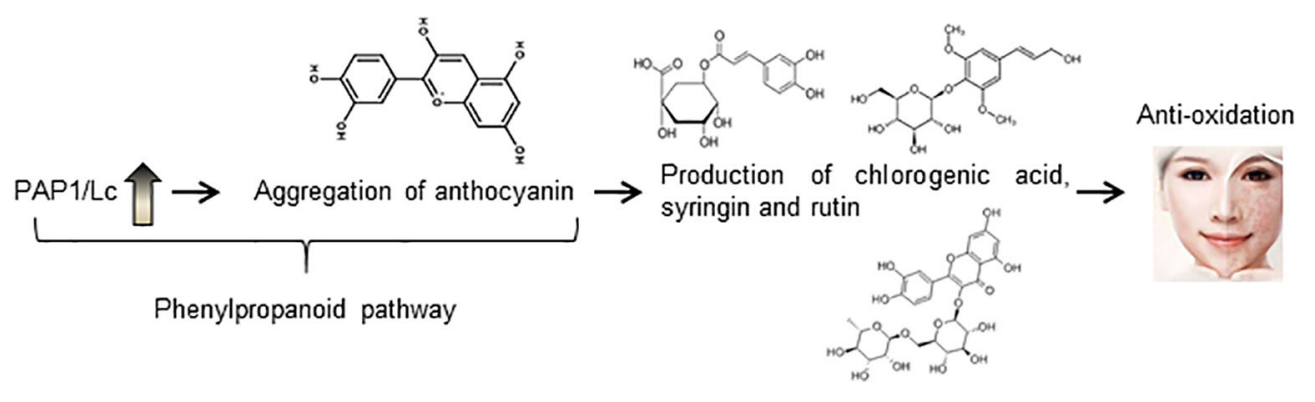

FIGURE 5 | Flow chart of phenylpropanoid pathways. PAP1/Lc up-regulates the biosynthetic pathway of anthocyanin, and which has the mentioned anti-oxidative functions. 
indispensable constituents in supporting the development of "Snow lotus" (Wu et al., 2010).

\section{BIOLOGICAL ACTIVITY OF "SNOW LOTUS"}

\section{Neuroprotection Effect}

"Snow lotus" was found to have therapeutic effects against severe acute pancreatitis (SAP)-induced brain injury using in vivo tests. In SAP-induced rats, administration of the extract of "Snow lotus" decreased the mortality rate. In parallel, the serum levels of endothelin-1 (ET-1) and nitric oxide (NO) were significantly reduced, as compared to the control group (Wang et al., 2018). Meanwhile, the pathological changes in pancreas and brain were milder, as comparing to SAP-untreated rats. It is also found that PI3K/Akt signaling pathway was associated with development and progression of SAP-induced brain injury. The intraperitoneal injection of "Snow lotus" extract in SAP-treated rats induced the protein expression of PI3K/Akt (Wang et al., 2018), which should be an indication of therapeutic function of "Snow lotus" in brain damage (Table 1). In another investigation on "Snow lotus" extract using D-galactose-induced brain injury mice, promising therapeutic functions were observed. After 6week of recovery with the herbal treatment in the injured mice, an enhancement of superoxide dismutase and glutathione peroxidase, as well as a decrease of lipid peroxidation, was revealed in the plasma (Yang et al., 2012). Furthermore, the ethyl acetate extract of "Snow lotus"-treated mice showed an improved behavioral performance in step-through passive avoidance task (Yang et al., 2012).

Acacetin, an o-methylated flavone from "Snow lotus" or other Asteraceae family (Zhao et al., 2016a), was shown to be a neuroprotective agent by suppression of depolarization-evoked glutamate release and cytosolic free $\mathrm{Ca}^{2+}$ concentration in the hippocampal nerve terminals, which was hypothesized to be prevented by Cav2.2 (N-type) and Cav2.1 (P/Q-type) channel blockers (Lin et al., 2014). Rutin was a predominant bioactive constituent found within "Snow lotus". Consumption of rutin was capable of alleviating the permanent bilateral common carotid artery occlusion (BCCAO) in rat model by revealing central cholinergic functions, oxidative stress-induced damages, inflammatory responses and neuronal damages in cerebral cortex and hippocampus (Qu et al., 2014). Besides, rutin was capable of modulating neurodegeneration by increasing production of neurotropic factors and attenuating rate of apoptosis ( $\mathrm{Na}$ et al., 2014). The presence of rutin decreased the acrylamide-induced cytotoxicity, as well as the amount of malondialdehyde, as compared to the control group (Motamedshariaty et al., 2014).

Anti-epileptic functions of hispidulin have been proposed to be one of distinctive characteristics in "Snow lotus". This chemical was shown to suppress the release of glutamate, activated by a specific $\mathrm{K}^{+}$channel blocker 4 -aminopyridine, and which restrained glutamate release from cortical synaptosome via presynaptic voltage-dependent $\mathrm{Ca}^{2+}$ entry and ERK/synapsin signaling blockage (Lin et al., 2012a). Treatment with hispidulin in cell cultures alleviated the bupivacaine-induced neurotoxicity cell injury via enhancing the activations of AMPK and GSK3 $\beta$ levels in mitochondrial membrane (Niu et al., 2014).

\section{Ischemia/Reperfusion Injury Protection}

Acacetin acts as a promising atrium-selective agent in treating atrial fibrillation. In human atrial myocytes, acacetin delayed rectifier $\mathrm{K}^{+}$current and transient outward $\mathrm{K}^{+}$current, as well as prolonging action potential. Besides, acacetin blocked the acetylcholine-activated $\mathrm{K}^{+}$current without affecting other cardiac currents ( $\mathrm{Li}$ et al., 2008). The water-soluble pro-drug, acacetin phosphate, was reported to protect rats from ischemia/ reperfusion injury (Table 2). Molecular analysis revealed that acacetin prevented the reduction of anti-oxidative kinases and

TABLE 1 | Summary of neuro-protection functions of "Snow lotus" and/or its major biochemical.

\begin{tabular}{|c|c|c|c|}
\hline Models & Parameters measured & Active components & Reference \\
\hline In vivo & ET-1 and NO content in serum & "Snow lotus" extract & Wang et al., 2018 \\
\hline In vivo & Behavioral test & Ethyl acetate extract of "Snow lotus" & Yang et al., 2012 \\
\hline In vivo & Cytosolic free $\mathrm{Ca}^{2+}$ concentration & Acacetin & Lin et al., 2014 \\
\hline In vivo/ in vitro & Oxidative stress-induced damage, inflammatory responses and neuronal & Rutin & Qu et al., 2014 \\
\hline In vivo & Malondialdehyde & Rutin & Motamedshariaty et al., 2014 \\
\hline In vivo & AMPK and GSK3 $\beta$ activations & Hispidulin & Niu et al., 2014 \\
\hline In vitro & Neurotropic factors production & Rutin & Na et al., 2014 \\
\hline In vitro & Glutamate activation & "Snow lotus" extract & Lin et al., $2012 a$ \\
\hline
\end{tabular}

TABLE 2 | Summary of ischemia/reperfusion injury protection of "Snow lotus" and/or its major biochemical.

\begin{tabular}{|c|c|c|c|}
\hline Models & Parameters measured & Active components & Reference \\
\hline In vivo & Acetylcholine-activated $\mathrm{K}+$ current & Acacetin & Li et al., 2008 \\
\hline In vivo & lipid peroxidation activation and infracts size & Rutin & Krishna et al., 2005; Annapurna et al., 2009; Ali et al., 2009 \\
\hline In vivo & cGMP, iNOS and 3-NT concentrations & Rutin & Korkmaz \& Kolankaya, 2013 \\
\hline In vitro/ in vivo & ROS formation and pro-inflammatory cytokine concentration & Acacetin & Wu et al., 2018 \\
\hline In vitro & Cytokine levels & Acacetin & Liu et al., 2016 \\
\hline
\end{tabular}


thioredoxin, and which therefore reduced the release of various inflammatory cytokines. The result of acacetin treatment was to suppress myocyte apoptosis, after induced by ischemia/ reperfusion (Liu et al., 2016). In addition, acacetin having a concentration ranging from 0.3 to $3.0 \mu \mathrm{M}$ was capable of declining cardiomyocyte apoptosis and reactive oxygen species (ROS) production by altering the ratio of Bax/Bcl-2 (Wu et al., 2018). Moreover, acacetin could induce the release of proinflammatory cytokines, e.g. TLR-4 and IL-6, in cultured H9C2 cells (Wu et al., 2018).

Rutin exhibits similar pharmaceutical functions as that of acacetin (Korkmaz \& Kolankaya, 2013; Lv et al., 2018). The pretreatment of rutin in rats dramatically attenuated cyclic guanosine monophosphate (cGMP) and NO level in serum and inhibited inducible nitric oxide synthase (iNOS) and 3nitrotyrosine (3-NT) formation in kidney (Korkmaz and Kolankaya, 2013). In addition, the cardio-protective functions of rutin by revealing ischemia-reperfusion-induced myocardial infarction were also reported in rats (Krishna et al., 2005; Ali et al., 2009; Annapurna et al., 2009). The intake of rutin showed the cardio-protection by restraining infract size in normal and diabetic rats: the underling action mechanism was believed to trigger lipid peroxidation in myocardial tissues (Krishna et al., 2005; Ali et al., 2009; Annapurna et al., 2009).

\section{Adipogenesis Suppression}

In high-fat-diet-induced (HFD) obese mice, acacetin reduced body weight and visceral adipose tissue. In differentiated 3T3-L1 cells, applied acacetin increased the level of glycerol in culture medium and significantly inhibited lipid accumulation by Oil Red $\mathrm{O}$ staining. In addition, acacetin reduced the transcript and protein expressions of adipogenesis-related transcription factors, including the CCAAT/enhancer-binding protein in cultured adipocytes. In parallel, acacetin treatment increased sirtuin 1 expression and AMPK phosphorylation (Liou et al., 2017). Besides, acacetin was able to suppress the levels of inflammatory mediators, as well as levels of MAPK and NF- $\mathrm{KB}$ pathways, in cultured macrophages, as treated with differentiated media deriving from cultured 3T3-L1 adipocytes ( $\mathrm{Su}$ et al., 2014a; Liou et al., 2017). In insulin-resistant adipocytes, acacetin treatment significantly reduced the levels of chemokines MCP-1 and CCL5 in these cells, as to restore the resistance (Liou et al., 2017).

Administration of rutin in mice could modulate obesity, fatty liver and insulin resistance by increasing energy-consuming gene expressions in brown adipose tissue, including Pgc1 $\alpha$ and Dio2, via up-regulating mitochondrial size and mitochondrial DNA (mtDNA) content, as well as those mitochondrial biogenesisrelated genes, i.e. peroxisome proliferator-activated receptor $\gamma$ (PARP $\gamma)$, coactivator-1 $\alpha$ (PGC- $1 \alpha)$ and nuclear respiratory factor-1 (NRF-1) (Gao et al., 2013; Seo et al., 2015). Furthermore, rutin also restricted the transcriptions of Srebp1c and $\mathrm{Cd} 36$, leading to a blockade of developing fatty liver (Gao et al., 2013). After oral administration of rutin in obese mice for 1 week, the rutin-treated group showed over 3-fold longer exhaustive swimming time than the blank control, and which, in parallel, significantly reduced the plasma content of lactic acid (Table 3). In rutin-treated mice, the rates of transcription and translation of PGC-1 $\alpha$ gene were enhanced in their soleus muscle, and these changes were associated with increased endurance capacity (Su et al., 2014b).

Hispidulin, another major flavonoid in "Snow lotus", was shown to possess therapeutic potential in against dyslipidemia. In cultured HepG2 cells, hispidulin acted as an agonist of PPAR $\alpha$ and regulated the downstream lipid-metabolizing enzymes, e.g. fatty-acid binding protein 1 and 2, acyl-CoA synthetase 1 , carnitine palmitoyltransferase $1 \alpha$, acetyl-CoA acetyltransferase 1 , acyl-coenzyme A dehydrogenase 1 and HMG-CoA synthase 2. In dyslipidemic rat model, the treatment of hispidulin significantly reduced total serum cholesterol, triglyceride and low-density lipoprotein cholesterol, as well as increasing the serum level of high-density lipoprotein cholesterol ( $\mathrm{Wu}$ and $\mathrm{Xu}, 2016$ ).

\section{Anti-Cancer Effect}

The anti-cancer properties of "Snow lotus" have been documented. In SK-Hep1 human hepatocellular carcinoma cell line, the cell proliferation was significantly inhibited by the ethanol extract of "Snow lotus" (Table 4). This treatment also caused cell cycle arrest at G1-phase, inhibition of DNA synthesis and apoptosis induction via caspase 3 and 9 signaling. (Byambaragchaa et al., 2014). In addition, the ethanol extract of "Snow lotus" showed anti-metastatic property by inhibiting invasion and motility of cancer cells via activation of an inhibitor for matrix metalloproteinase-2/-9 (MMP-2/-9) (Byambaragchaa et al., 2013). The anti-neoplastic activity of different herbal extracts deriving from "Snow lotus" was shown in PC-3 prostate cancer cells, which included the herbal fractions by using extracting solvents of methanol, ethyl acetate, n-butanol and water. Among these extractives, the ethyl acetate extract showed the most promising effect in inhibiting cancer cell $(\mathrm{Yu}$

TABLE 3 | Summary of adipogenesis suppression effects of "Snow lotus" and/or its major biochemical.

\begin{tabular}{|c|c|c|c|}
\hline Models & Parameters measured & $\begin{array}{l}\text { Active } \\
\text { components }\end{array}$ & Reference \\
\hline In vivo/in vitro & Body and visceral adipose tissue weight; AMPK phosphorylation, MCP-1 and CCL5 contents & Acacetin & Liou et al., 2017 \\
\hline In vivo/in vitro & mtDNA content; PARP $\gamma$, PGC-1 $\alpha$ and NRF-1 transcriptional and translational effects & Rutin & Gao et al., 2013; Seo et al., 2015 \\
\hline In vivo/in vitro & Total serum cholesterol, triglyceride and low-density lipoprotein cholesterol and PPAR $\alpha$ activations & Hispidulin & Wu and Xu, 2016 \\
\hline In vivo & Srebp1c and Cd36 levels & Rutin & Gao et al., 2013 \\
\hline In vivo & Exhaustive swimming time & Rutin & Su et al., 2014b \\
\hline In vitro & Inactivation of MAPK and NF- $\kappa$ B pathways & Acacetin & Su et al., $2014 a$ \\
\hline
\end{tabular}


TABLE 4 | Summary of anti-cancer functions of "Snow lotus" and/or its major biochemicals.

\begin{tabular}{|c|c|c|c|}
\hline Models & Parameters measured & Active components & Reference \\
\hline In vivo/ in vitro & Prolong the lifespan of xenograft nude mice & Rutin & Alonso-Castro et al., 2013; Chen et al., 2013 \\
\hline In vivo & $\begin{array}{l}\text { Capillary-like tube formation and down regulation of } \\
\text { VEGF expression }\end{array}$ & Acacetin & Liu et al., 2011; Bhat et al., 2013 \\
\hline In vivo & $\begin{array}{l}\text { Suppressing PC-3 cancer and reducing EGFR } \\
\text { activation in prostate cancer }\end{array}$ & "Snow lotus" extract & Way et al., 2010; Yu et al., 2013 \\
\hline In vitro & Cell invasion and motility & Rutin Acacetin Hispidulin & $\begin{array}{l}\text { Pan et al., 2005; Araújo et al., 2011; Byambaragchaa } \\
\text { et al., 2013; Yu et al., 2013; Kim H et al., 2014; Gao } \\
\text { et al., 2014; Kim C et al., } 2015\end{array}$ \\
\hline In vitro & Cell cycle, DNA synthesis & "Snow lotus" extract & Byambaragchaa et al., 2014 \\
\hline In vivo & Tumor size and SphK1 & Hispidulin and rutin & Lin et al., 2012b; Gao et al., 2017 \\
\hline
\end{tabular}

et al., 2013). More importantly, the ethyl acetate extract of "Snow lotus" markedly reduced the phosphorylation of epidermal growth factor receptor, one of the therapy targets for prostate cancer (Way et al., 2010).

Acacetin has been shown to induce apoptosis and suppress cell proliferation in gastric carcinoma, oral squamous carcinoma and prostate cancer cells (Pan et al., 2005; Kim H et al., 2014; Kim C et al., 2015). This chemical suppressed the growth of human umbilical vein endothelial cell and the formation of capillary-like tube (Bhat et al., 2013). Acacetin also blocked the phosphorylations of Stat-1 (Tyr701) and Stat-3 (Tyr705), as well as restrained the expression levels of pro-angiogenic factors, e.g. VEGF, eNOS, iNOS, MMP-2 and bFGF, in cancer cells (Bhat et al., 2013). Moreover, over-expression of HIF-1 $\alpha$ or AKT inhibited acacetin-restraining VEGF protein level, demonstrating that AKT and HIF- $1 \alpha$ could be the downstream key factors in suppressing VEGF expression in ovarian cancer cell (Liu et al., 2011).

Hispidulin is being considered as a potential compound in treating gastric cancer and hepatocellular carcinoma (Yu et al., 2013; Gao et al., 2014). The treatment of hispidulin in AGS human gastric adenocarcinoma cell line could reduce cyclooxygenase-2 (COX-2) expression while keeping a high expression of nonsteroidal-anti-inflammatory-drug-(NSAID-) activated gene-1 (NAG-1). NAG-1 is known to be associated with apoptosis, and the down regulation of this protein expression may promote tumorigenesis (Table 4). In NAG-1 constitutive expressed cells, the G1/S phase was arrested, as well as inducing cancer cell apoptosis: this outcome was proposed to be mediated by increased expression of Egr-1 and activated ERK1/2 signaling (Yu et al., 2013). In accordance to anticancer notion of hispidulin, Gao and co-workers (Gao et al., 2013) demonstrated that the hispidulin-triggered apoptosis in HepG2 cells could be mediated by the mitochondrial dysfunction, as well as the blockage of P13K/Akt pathway. Subsequently, they showed that hispidulin also prevented proliferation of acute myeloid leukemia cell and triggered cell death via an intrinsic mitochondrial pathway by restraining the extracellular matrix metalloproteinase inducer (Gao et al., 2016). Injection of hispidulin in xenograft nude mice in a dosedependently inhibited tumor size and decreased SphK1 activity, as well as an increase of ceramide accumulation in tumor tissues (Gao et al., 2017).
Excessive anti-cancer functions of rutin have been reported. Rutin dramatically suppressed tumor size justifying antileukemic potential in xenograft nude mice (Lin et al., 2012b). Another in vivo study has shown that the rutin application reduced detrimental effects and relative organ weight in mice, and more importantly, the increment of mean survival time was observed (Alonso-Castro et al., 2013). In vitro study demonstrated the altered $\mathrm{Bax} / \mathrm{Bcl} 2$ ratio in cultured $\mathrm{LAN}-5$ cell after the treatment of rutin (Chen et al., 2013). Moreover, rutin was known to induce cancer cell apoptosis along with proliferation, angiogenesis and/or metastasis inhibition in colorectal cell lines (Araújo et al., 2011).

\section{Anti-Inflammation}

According to TCM and/or TUM, the extract of "Snow lotus" has been used as a therapeutic agent for inflammation and painrelated disorders. Recent studies have helped to reveal the signaling mechanism contributing in such pharmacological effects. Yi and co-workers had demonstrated that the ethanolic extract of "Snow lotus" possessed anti-inflammatory and antinociceptive functions in a mouse model of croton oil-induced ear edema (Yi et al., 2012). In parallel, the oral administration of "Snow lotus" extract was used to treat rats suffering from the collagen II (CII)-induced arthritis (Xu et al., 2016): the infiltration of inflammatory cell, synovial hyperplasia, swelling index and delaying joint destruction were found to be alleviated (Table 5). The serum levels of rheumatoid factor, cartilage oligomeric matrix protein (COMP), C-reactive protein and anti-CII IgG antibodies were significantly reduced. Moreover, the therapeutic effects on rheumatoid arthritis by alcohol and water extractives of "Snow lotus" were compared. The effect of ethanolic extract was more potent than that of water extract in treating rheumatoid arthritis in rat model. The ethanolic herbal extract significantly ameliorated rheumatoid arthritis severity, and the over productions of cytokines, e.g. TNF- $\alpha$, IL-1 $\beta$, and IL-6, were markedly attenuated in the serum of "Snow lotus" intake rats (Han et al., 2016). Yi and co-workers (2012) presented similar results in in vitro analysis of the ethanolic herbal extract: the application of extract in cultures suppressed ROS formation significantly, and the IC50 was $409.6 \mathrm{mg} / \mathrm{L}$. Xiao and co-workers (2011) showed that application of "Snow lotus" extract on cultured macrophage could reduce the levels of PGE2 and NO from $294.9 \mathrm{ng} / \mathrm{mL}$ to 
TABLE 5 | Summary of anti-inflammatory functions of "Snow lotus" and/or its major biochemical.

\begin{tabular}{|c|c|c|c|}
\hline Models & Parameters measured & Active components & Reference \\
\hline In vivo & $\begin{array}{l}\text { Synovial hyperplasia, swelling index, joint destruction and } \\
\text { serum cytokine levels }\end{array}$ & "Snow lotus" and rutin & $\begin{array}{l}\text { Chen et al., 2014b; Xu et al., 2016; Han } \\
\text { et al., } 2016\end{array}$ \\
\hline In vivo & Eosinophil infiltration and goblet cell hyperplasia in lung tissue & "Snow lotus" extract & Huang and Liou, 2012 \\
\hline In vivo & ROS formation & Rutin & $\begin{array}{l}\text { Guardia et al., 2001; Ostrakhovitch and } \\
\text { Afanas'ev, } 2001\end{array}$ \\
\hline In vivo & $\begin{array}{l}\text { Skin rush and inflammation Epidermal hyperplasia and protein } \\
\text { level }\end{array}$ & Rutin & Choi et al., 2014; Gęgotek et al., 2017 \\
\hline
\end{tabular}

$238.6 \mathrm{ng} / \mathrm{mL}$ and $6.61 \mathrm{ng} / \mathrm{mL}$ to $4.52 \mathrm{ng} / \mathrm{mL}$, respectively. Another study illustrated the action of acacetin in mitigating airway hyper-responsiveness in asthmatic mice. The treatment of acacetin reduced the levels of chemokines and Th2-associated cytokines in asthmatic mice, and which effectively suppressed eosinophil infiltration and goblet cell hyperplasia in lung tissue (Huang and Liou, 2012).

The pre-treatment of rutin declined the lipopolysaccharide (LPS)-induced arterial blood gas exchange and neutrophils infiltration in vivo, and also restrained macrophage inflammatory protein-2 and MMP-9 secretion (Chen et al., 2014b). Significantly decrement in rheumatoid arthritis scores by restraining ROS formation were observed in the rutin-treated rats, and these findings were in line with the rat model of adjuvant arthritis. In addition, rutin inhibited the duplicate inflammatory phases, i.e. acute and chronic stages (Guardia et al., 2001; Ostrakhovitch and Afanas'ev, 2001). Besides, the skin care functions of rutin have been explored to demonstrate the pharmaceutical values of rutin on ultraviolet B (UVB)induced inflammation in vivo (Choi et al., 2014). Pre-treatment and post-treatment of rutin with UVB declined epidermal hyperplasia and protein level in mice (Choi et al., 2014; Gęgotek et al., 2017). Furthermore, rutin suppressed UVBinduced expressions of COX-2 and iNOS through p38 MAP kinase and JNK inhibition.

\section{Other Pharmaceutical Values}

"Snow lotus" is classified as a "kidney-tonifying" in TCM practice, and which is being applied to treat osteoarthritis, articular cartilage injury and osteoporosis with a long history. In a herbal mixture having "Snow lotus" and three other "kidneytonifying" TCMs, i.e. Astragali Radix, Salviac Miltiorhizae Radix \& Rhzizoma and Epimedii Herba, is known to promote the proliferation and osteogenic differentiation of bone marrowderived mesenchymal stem cells (BMSCs) (Cai et al., 2015). Rutin stimulated proliferation and differentiation of osteosarcoma MG-63 cells by analyzing the increase of cell viability, alkaline phosphatase (ALP), collagen type I and mineralization (Hyun et al., 2014). Similar pharmaceutical functions of rutin have been reported in rat calvarial osteoblast cells (Yang et al., 2006). Osteoclast growth, ROS formation and cytokine secretion were being restricted in the rutin-treated bone cultures (Kyung et al., 2008). Rutin also inhibited the ovariectomy-induced osteopenia in rats by accelerating the formation of osteoblast (Horcajada-Molteni et al., 2000).
Hispidulin has estrogenic and anti-osteoporosis functions, and which could act as a promising medicine for osteoporosis modulation. The application of hispidulin in ovariectomy rat model could attenuate bone loss after 2 months of treatment (Zhou et al., 2014). In hispidulin-treated cultures, activated ALP activity was revealed in cultured MC3T3E1 cells, and additionally osteoclastic activity was suppressed in cultured RAW 264.7 cell via prohibiting RANKL-induced activation of JNK and p38 (Nepal et al., 2013).

\section{CONCLUSION}

The pharmaceutical functions of S. involucrata (a TUM and/or a TCM herbal material) and its key bioactive chemical ingredients, identified and isolated from this herb, were summarized and reviewed here. These known pharmaceutical properties include immune-modulation, anti-inflammation, adipogenesis inhibition, neuroprotection and ischemia injury protection. Due to its distinct habitat, the resource of "Snow lotus" is rather rare. The plant grows at over $4,000 \mathrm{~m}$ altitude in mountainous rocky environment under rather harsh climatic conditions. The plant takes over 8 years to mature before the harvest. Furthermore, over harvesting in China is destroying the growing environment and causing the damage of $S$. involucrata species quality. As a result, these are the major reasons for rarity of "Snow lotus" in the market. The cultivation of "Snow lotus" has been tried by the Xinjiang Technical Institute of Physics \& Chemistry in China, the results showed that the harvest period could be shorten from 8 years to 2 years, and the major chemical contents were not decreased. Furthermore, the standard operating procedure of artificial cultivation of "Snow lotus" has been established today, and the cultivation has already extended to $4,000 \mathrm{~m}$ altitude. Besides, there are many "Snow lotus" products being available in current herbal market, including cosmeceuticals, food supplements and medications. Although there have been many studies and researches on "Snow lotus", future research can be carried out in two directions. Firstly, active components, morphological identification, pharmacological effects and metabolisms need to be explored based on the studies of S. involucrat and S. laniceps (Chen et al., 2014a; Fan et al., 2015; Chen et al., 2016; Yi et al., 2016; Chen et al., 2017). Secondly, in order to extract these active components as much as possible from "Snow lotus", the potential approaches to pre-treat the extracts could be considered, such as pre-soaking, liquid 
ammonia pre-treatment and co-digestion (Zhao et al., 2016b; Hassan et al., 2017; Zhao et al., 2017a; Zhao et al., 2017b; Qiao et al., 2018). Innovative technology in these areas of research are urgently needed.

\section{AUTHOR CONTRIBUTIONS}

GG, KC, and KT wrote the main text. JH and TD had great contribution in second time revision, polishing manuscript and helping in revising figures.

\section{REFERENCES}

Ali, M. S., Mudagal, M. P., and Goli, D. (2009). Cardioprotective effect of tetrahydrocurcumin and rutin on lipid peroxides and antioxidants in experimentally induced myocardial infarction in rats. Pharmazie. 64, 132-136

Alonso-Castro, A. J., Domínguez, F., and García-Carrancá, A. (2013). Rutin exerts antitumor effects on nude mice bearing SW480 tumor. Arch. Med. Res. 44, 346-351. doi: 10.1016/j.arcmed.2013.06.002

Annapurna, A., Reddy, C. S., Akondi, R. B., and Rao, S. R. (2009). Cardioprotective actions of two bioflavonoids, quercetin and rutin, in experimental myocardial infarction in both normal and streptozotocin-induced type I diabetic rats. J. Pharm. Pharmacol. 61, 1365-1374. doi: 10.1211/jpp/61.10.0014

Araújo, J. R., Gonçalves, P., and Martel, F. (2011). Chemopreventive effect of dietary polyphenols in colorectal cancer cell lines. Nutr. Res. 31, 77-87. doi: 10.1016/j.nutres.2011.01.006

Bhat, T. A., Nambiar, D., Tailor, D., Pal, A., Agarwal, R., and Singh, R. P. (2013). Acacetin inhibits in vitro and in vivo angiogenesis and down-regulates Stat signaling and VEGF expression. Cancer Prev. Res. (Phila). 6, 1128-1139. doi: 10.1158/1940-6207.CAPR-13-0209

Byambaragchaa, M., Dela Cruz, J., Yang, S. H., and Hwang, S. G. (2013). Antimetastatic potential of ethanol extract of Saussurea involucrata against hepatic cancer in vitro. Asian Pac J. Cancer Prev. 14, 5397-5402. doi: 10.7314/ apjcp.2013.14.9.5397

Byambaragchaa, M., Dela Cruz, J., Kh, A., and Hwang, S. G. (2014). Anti-cancer potential of an ethanol extract of Saussurea involucrata against hepatic cancer cells in vitro. Asian Pac J. Cancer Prev. 15, 7527-7532. doi: 10.7314/ apjcp.2014.15.18.7527

Cai, B., Zhang, A. G., Zhang, X., Ge, W. J., Dai, G. D., Tan, X. L., et al. (2015). Promoting effects on proliferation and chondrogenic differentiation of bone marrow-derived mesenchymal stem cells by four "Kidney-Tonifying" traditional Chinese herbs. BioMed. Res. Int. 2015, 792161. doi: 10.1155/2015/792161

Chen, J., and Wang, Y. J. (2018). New Saussurea (Asteraceae) species from Bogeda Mountain, eastern Tianshan, China, and inference of its evolutionary history and medical usage. PloS One 13, e0199416. doi: 10.1371/journal.pone.0199416

Chen, Y. S., Hu, Q. H., Zhang, X., Zhu, Q., and Kong, L. D. (2013). Beneficial effect of rutin on oxonate-induced hyperuricemia and renal dysfunction in mice. Pharmacology 92, 75-83. doi: 10.1159/000351703

Chen, Q. L., Yi, T., Tang, Y. N., Wong, L. L., Huang, X. X., Zhao, Z. Z., et al. (2014a). Comparative authentication of three "Snow Lotus" herbs by macroscopic and microscopic features. Microsc Res. Techniq. 77, 631-641. doi: $10.1002 /$ jemt. 22381

Chen, W. Y., Huang, Y. C., Yang, M. L., Lee, C. Y., Chen, C. J., Yeh, C. H., et al. (2014b). Protective effect of rutin on LPS-induced acute lung injury via downregulation of MIP-2 expression and MMP-9 activation through inhibition of Akt phosphorylation. Int. Immunopharmacol. 22, 409-413. doi: 10.1016/ j.intimp.2014.07.026

Chen, Q. L., Chen, X.,. Y., Zhu, L., Chen, H. B., Ho, H. M., Yeung, W. P., et al. (2016). Review on Saussurea laniceps, a potent medicinal plant known as "snow lotus": botany, phytochemistry and bioactivities. Phytochem. Rev. 15, 537-565. doi: 10.1007/s11101-015-9452-y

Chen, Q. L., Zhu, L., Tang, Y. N., Kwan, H. Y., Zhao, Z. Z., Chen, H. B., et al. (2017). Comparative evaluation of chemical profiles of three representative "snow lotus" herbs by UPLC-DAD-QTOF-MS combined with principal component and hierarchical cluster analyses. Drug Test Anal. 9, 1105-1115. doi: 10.1002/dta.2123

\section{FUNDING}

Supported by Research Fund of Zunyi Medical University for the Doctoral Program (F-937), NNSF of Guangdong (2018A030307074), Science and Technology Planning Project of Guangdong (2014A020221058), China. Shenzhen Science and Technology Innovation Committee (JCYJ20160229205812004; ZDSYS201707281432317; JCYJ20170413173747440; JCYJ20180306174903174). Scientific Research and Innovation of Putian University (2018ZP03, 2018ZP08, 2018ZP07).

Chen, J., Zhao, Y. B., Wang, Y. J., and Li, X. G. (2019). Identification of species and materia medica within Saussurea subg. Amphilaena based on DNA barcodes. PeerJ. 7, e6357. doi: 10.7717/peerj.6357

Chik, W. I., Zhu., L., Fan., L. L., Yi, T., Zhu, G. Y., Gou, X. J., et al. (2015). Saussurea involucrata: a review of the botany, phytochemistry and ethnopharmacology of a rare traditional herbal medicine. J. Ethnopharmacol. 172, 44-60. doi: 10.1016/j.jep.2015.06.033

Choi, K. S., Kundu, J. K., Chun, K. S., Na, H. K., and Surh, Y. J. (2014). Rutin inhibits UV-B radiation-induced expression of COX-2 and iNOS in hairless mouse skin: p38 MAP kinase and JNK as potential targets. Arch. Biochem. Biophys. 559, 38-45. doi: 10.1016/j.abb.2014.05.016

Fan, J. Y., Chen, H. B., Zhu, L., Chen, H. L., Zhao, Z. Z., and Yi, T. (2015). Saussurea medusa, source of the medicinal herb snow lotus: a review of its botany, phytochemistry, pharmacology and toxicology. Phytochem. Rev. 14, 353-366. doi: 10.1007/s11101-015-9408-2

Gęgotek, A., Bielawska, K., Biernack, M., Dobrzyńska, I., and Skrzydlewska, E. (2017). Time-dependent effect of rutin on skin fibroblasts membrane disruption following UV radiation. Redox Biol. 12, 733-744. doi: 10.1016/j.redox.2017.04.014

Gao, M., Ma, Y., and Liu, D. (2013). Rutin suppresses palmitic acids-triggered inflammation in macrophages and blocks high fat diet-induced obesity and fatty liver in mice. Pharm. Res. 30, 2940-2950. doi: 10.1007/s11095-013-1125-1

Gao, H., Wang, H., and Peng, J. (2014). Hispidulin induces apoptosis through mitochondrial dysfunction and inhibition of P13k/Akt signaling pathway in HepG2 cancer cells. Cell Biochem. Biophys. 69, 27-34. doi: 10.1007/s12013013-9762-X

Gao, H., Liu, Y., Li, K., Wu, T., Peng, J., and Jing, F. (2016). Hispidulin induces mitochondrial apoptosis in acute myeloid leukemia cells by targeting extracellular matrix metalloproteinase inducer. Am. J. Transl. Res. 8, 1115-1132.

Gao, M., Gao, H., Han, M., Liu, K., Peng, J., and Han, Y. (2017). Hispidulin suppresses tumor growth and metastasis in renal cell carcinoma by modulating ceramide-sphingosine 1-phosphate rheostat. Am. J. Cancer Res. 7, 1501-1514.

Guardia, T., Rotelli, A. E., Juarez, A. O., and Pelzer, L. E. (2001). Anti-inflammatory properties of plant flavonoids. effects of rutin, quercetin and hesperidin on adjuvant arthritis in rat. Farmaco. 56, 683-687. doi: 10.1016/s0014-827x(01)01111-9

Han, X., Su, D., Xian, X., Zhou, M., Li, X., Huang, J., et al. (2016). Inhibitory effects of Saussurea involucrata (Kar. et Kir.) Sch. -Bip. on adjuvant arthritis in rats. J. Ethnopharmacol. 194, 228-235. doi: 10.1016/j.jep.2016.09.008

Hassan, M., Umar, M., Ding, W. M., Mehryar, E., and Zhao, C. (2017). Methane enhancement through co-digestion of chicken manure and oxidative cleaved wheat straw: Stability performance and kinetic modeling perspectives. Energy. 141, 2314-2320. doi: 10.1016/j.energy.2017.11.110

Horcajada-Molteni, M. N., Crespy, V., Coxam, V., Davicco, M. J., Rémésy, C., and Barlet, J. P. (2000). Rutin inhibits ovariectomy-induced osteopenia in rats. J. Bone Miner Res. 15, 2251-2258. doi: 10.1359/jbmr.2000.15.11.2251

Huang, W. C., and Liou, C. J. (2012). Dietary acacetin reduces airway hyper responsiveness and eosinophil infiltration by modulating eotaxin-1 and th2 cytokines in a mouse model of asthma. Evid Based Complement Alternat Med. 2012, 910520. doi: 10.1155/2012/910520

Hyun, H., Park, H., Jeong, J., Kim, J., Kim, H., Oh, H., et al. (2014). Effects of watercress containing rutin and rutin alone on the proliferation and osteogenic differentiation of human osteoblast-like MG-63 cells. Korean J. Physiol. Pharmacol. 18, 347-352. doi: 10.4196/kjpp.2014.18.4.347

Kim, H. R., Park, C. G., and Jung, J. Y. (2014). Acacetin (5,7-dihydroxy-4'methoxyflavone) exhibits in vitro and in vivo anticancer activity through the 
suppression of NF-kappaB/Akt signaling in prostate cancer cells. Int. J. Mol. Med. 33, 31-324. doi: 10.3892/ijmm.2013.1571

Kim, C. D., Cha, J. D., Li, S., and Cha, I. H. (2015). The mechanism of acacetin-induced apoptosis on oral squamous cell carcinoma. Arch. Biol. 60, 1283-1298. doi: 10.1016/j.archoralbio.2015.05.009

Korkmaz, A., and Kolankaya, D. (2013). Inhibiting inducible nitric oxide synthase with rutin reduces renal ischemia/reperfusion injury. Can. J. Surg. 56, 6-14. doi: $10.1503 /$ cjs.004811

Krishna, K. M., Annapurna, A., Gopal, G. S., Chalam, C. R., Madan, K., Kumar, V. K., et al. (2005). Partial reversal by rutin and quercetin of impaired cardiac function in streptozotocin-induced diabetic rats. Can. J. Physiol. Pharmacol. 83, 343-355. doi: 10.1139/y05-009

Kyung, T., Lee, J., Shin, H., and Choi, H. (2008). Rutin inhibits osteoclast formation by decreasing reactive oxygen species and TNF- $\alpha$ by inhibiting activation of NF-KB. Exp. Mol. Med. 40, 52-58. doi: 10.3858/emm.2008.40.1.52

Li, G. R., Wang, H. B., Qin, G. W., Jin, M. W., Tang, Q., Sun, H. Y., et al. (2008). Acacetin, a natural flavone, selectively inhibits human atrial repolarization potassium currents and prevents atrial fibrillation in dogs. Circulation. 117, 2449-2457. doi: 10.1161/CIRCULATIONAHA.108.769554

Lin, T. Y., Lu, C. W., Wang, C. C., Lu, J. F., and Wang, S. J. (2012a). Hispidulin inhibits the release of glutamate in rat cerebrocortical nerve terminals. Toxicol. Appl. Pharmacol. 263, 233-243. doi: 10.1016/j.taap.2012.06.015

Lin, J. P., Yang, J. S., Lin, J. J., Lai, K. C., Lu, H. F., Ma, C. Y., et al. (2012b). Rutin inhibits human leukemia tumor growth in a murine xenograft model in vivo. Environ. Toxicol. 27, 480-484. doi: 10.1002/tox.20662

Lin, T. Y., Huang, W. J., Wu, C. C., Lu, C. W., and Wang, S. J. (2014). Acacetin inhibits glutamate release and prevents kainic acid-induced neurotoxicity in rats. PloS One 9, e88644. doi: 10.1371/journal.pone.0088644

Liou, C. J., Wu, S. J., Chen, L. C., Yeh, K. W., Chen, C. Y., and Huang, W. C. (2017). Acacetin from traditionally used Saussurea involucrata Kar. et Kir. suppressed adipogenesis in 3T3-L1 dipocytes and attenuated lipid accumulation in obese mice. Front. Pharmacol. 8, 589. doi: 10.3389/fphar.2017.00589

Liu, L. Z., Jing, Y., Jiang, L., Jiang, X., Jiang, Y., Rojanasakul, Y., et al. (2011). Acacetin inhibits VEGF expression, tumor angiogenesis and growth through AKT/HIF-1 $\alpha$ pathway. Biochem. Biophys. Res. Commun. 413, 299-305. doi: 10.1016/j.bbrc.2011.08.091

Liu, H., Yang, L., Wu, H. J., Chen., K. H., Lin, F., Li, G., et al. (2016). Water-soluble acacetin prodrug confers significant cardioprotection against ischemia/ reperfusion injury. Sci. Rep. 6, 36435. doi: 10.1038/srep36435

Lv, Y. L., Zhang, F. S., Chen, J., Cui, J. L., Xing, Y. M., Li, X. D., et al. (2010). Diversity and antimicrobial activity of endophytic fungi associated with the alpine plant Saussurea involucrata. Biol. Pharm. Bull. 33, 1300-1306. doi: $10.1248 / \mathrm{bpb} .33 .1300$

Lv, L., Yao, Y., Zhao, G., and Zhu, G. (2018). Rutin inhibits coronary heart disease through ERK1/2 and Akt signaling in a porcine model. Exp. Ther. Med. 15, 506-512. doi: 10.3892/etm.2017.5365

Motamedshariaty, V. S., Farzad, S. A., Nassiri-Asl, M., and Hosseinzadeh, H. (2014). Effects of rutin on acrylamide-induced neurotoxicity. Daru. 22, 27. doi: 10.1186/2008-2231-22-27

Na, J. Y., Kim, S., Song, K., and Kwon, J. (2014). Rutin alleviates prion peptideinduced cell death through inhibiting apoptotic pathway activation in dopaminergic neuronal cells. Cell Mol. Neurobiol. 34, 1071-1079. doi: 10.1007/s10571-014-0084-3

Nepal, M., Choi, H. J., and Choi, B. Y. (2013). Hispidulin attenuates bone resorption and osteoclastogenesis via the RANKL-induced NF-KB and NFATc1 pathways. Eur. J. Pharmacol. 715, 96-104. doi: 10.1016/ j.ejphar.2013.06.002

Niu, X., Chen, J., Wang, P., Zhou, H., Li, S., and Zhang, M. (2014). The effects of hispidulin on bupivacaine-induced neurotoxicity: role of AMPK signaling pathway. Cell Biochem. Biophys. 70, 241-249. doi: 10.1007/s12013-014-9888-5

Ostrakhovitch, E. A., and Afanas'ev, I. B. (2001). Oxidative stress in rheumatoid arthritis leukocytes: suppression by rutin and other antioxidants and chelators. Biochem. Pharmacol. 62, 743-746. doi: 10.1016/s0006-2952(01)00707-9

Packer, L., Ong, C. N., and Halliwell, B. (2004). Herbal and traditional medicine, molecular aspects of health (New York: Marcel Dekker), 2.

Pan, M. H., Lai, C. S., Hsu, P. C., and Wang, Y. J. (2005). Acacetin induces apoptosis in human gastric carcinoma cells accompanied by activation of caspase cascades and production of reactive oxygen species. J. Agric. Food Chem. 53, 620-630. doi: 10.1021/jf048430m

Qiao, X. L., Zhao, C., Shao, Q. J., and Hassan, M. (2018). Structural characterization of corn stover lignin after hydrogen peroxide presoaking prior to ammonia fiber expansion pretreatment. Energ Fuel. 32, 6022-6030. doi: 10.1021/acs.energyfuels.8b00951

Qiu, J., Xue, X., Chen, F., Li, C., Bolat, N., Wang, X., et al. (2010). Quality evaluation of Snow Lotus (Saussurea): quantitative chemical analysis and antioxidant activity assessment. Plant Cell Rep. 29, 1325-1337. doi: 10.1007/ s00299-010-0919-4

Qiu, J., Gao, F., Shen, G., Li, C., Han, X., Zhao, Q., et al. (2013). Metabolic engineering of the phenylpropanoid pathway enhances the antioxidant capacity of Saussurea involucrata. PloS One 8, e70665. doi: 10.1371/ journal.pone.0070665

Qu, J., Zhou, Q., Du, Y., Zhang, W., Bai, M., Zhang, Z., et al. (2014). Rutin protects against cognitive deficits and brain damage in rats with chronic cerebral hypoperfusion. Br. J. Pharmacol. 171, 3702-3715. doi: 10.1111/bph.12725

Seo, S., Lee, M., Chang, E., Shin, Y., Oh, S., Kim, I., et al. (2015). Rutin increases muscle mitochondrial biogenesis with AMPK activation in high-fat dietinduced obese rats. Nutrients. 7, 8152-8169. doi: 10.3390/nu7095385

Shahabi, S., Hassan, Z. M., Mahdavi, M., Dezfouli, M., Torabi, R. M., and Naseri, M. (2008). Hot and cold matures and some parameters of neuroendocrine and immune systems in traditional Iranian medicine: a preliminary study. J. Altern. Complement Med. 14, 147-156. doi: 10.1089/ acm.2007.0693

Su, K. Y., Yu, C. Y., Chen, Y. W., Huang, Y. T., Chen, C. T., Wu, H. F., et al. (2014a). Rutin, a flavonoid and principal component of Saussurea involucrata, attenuates physical fatigue in a forced swimming mouse model. Int. J. Med. Sci. 11, 528-537. doi: 10.7150/ijms.8220

Su, K. Y., Yu, C. Y., Chen, Y. P., Hua, K. F., and Chen, Y. L. (2014b). 3,4Dihydroxytoluene, a metabolite of rutin, inhibits inflammatory responses in lipopolysaccharide-activated macrophages by reducing the activation of NF-KB signaling. BMC Complement Altern. Med. 14, 21. doi: 10.1186/14726882-14-21

Tang, Y., Yuan, H., and Qin, J. (2012). Identification and characterization of a flavonoid-3-O-glucosyltransferase gene from Saussurea involucrata. Sheng $W u$ Gong Cheng Xue Bao. 28, 705-714.

Upur, H., Yusup, A., Baudrimont, I., Umar, A., Berke, B., Yimit, D., et al. (2011). Inhibition of cell growth and cellular protein, DNA and RNA synthesis in human hepatoma (HepG2) cell by ethanol extract of abnormal Savda Munziq of traditional Uighur medicine. Evid Based Complement Alternat Med. 2011, 251424. doi: 10.1093/ecam/nen062

Wang, C., Ha, X., Li, W., Xu, P., Gu, Y., Wang, T., et al. (2016). Correlation of A2bAR and KLF4/KLF15 with obesity-dyslipidemia induced inflammation in Uygur population. Mediators Inflamm. 7015620. doi: 10.1155/2016/7015620

Wang, X., Chu, L., Liu, C., Wei, R., Xue, X., Xu, Y., et al. (2018). Therapeutic effects of Saussurea involucrata injection against severe acute pancreatitis-induced brain injury in rats. BioMed. Pharmacother. 100, 564-574. doi: 10.1016/ j.biopha.2018.02.044

Way, T. D., Lee, J. C., Kuo, D. H., Fan, L. L., Huang, C. H., Lin, H. Y., et al. (2010). Inhibition of epidermal growth factor receptor signaling by Saussurea involucrata, a rare traditional Chinese medicinal herb, in human hormoneresistant prostate cancer PC-3 cells. J. Agric. Food Chem. 58, 3356-3365. doi: $10.1021 /$ jf $903793 p$

Wu, X., and Xu, J. (2016). New role of hispidulin in lipid metabolism: PPAR $\alpha$ activator. Lipids 51, 1249-1257. doi: 10.1007/s11745-016-4200-7

Wu, L. Q., Lv, Y. L., Meng, Z. X., Chen, J., and Guo, S. X. (2010). The promoting role of an isolate of dark-septate fungus on its host plant Saussurea involucrata Kar. et Kir. Mycorrhiza. 20, 127-135. doi: 10.1007/s00572-009-0268-8

Wu, W. Y., Li, Y. D., Cui, Y. K., Wu, C., Hong, Y. X., Li, G., et al. (2018). The natural flavone acacetin confers cardiomyocyte protection against hypoxia/ reoxygenation injury via AMPK-mediated activation of Nrf2 signaling pathway. Front. Pharmacol. 9, 497. doi: 10.3389/fphar.2018.00497

Xiao, W., Li, N., Bolati, M., Wang, X. J., Jia, X. G., and Zhao, Y. Q. (2011). Advances in studies on chemical components and pharmacological activities of Saussurea Involucratae Herba. Drugs Clin. 26, 344-348. doi: 10.1016/ j.ejphar.2011.05.061 
Xu, M., Guo, Q., Wang, S., Wang, N., Wei, L., and Wang, J. (2016). Antirheumatoid arthritic effects of Saussurea involucrata on type II collageninduced arthritis in rats. Food Funct. 7, 763-770. doi: 10.1039/c5fo00603a

Yang, Y. J., Yang, Z. L., Wang, D. C., Xiao, X. C., and Li, P. (2006). Comparative study on effects of rutin and quercetin on metabolism in osteoblast cells. Zhong Yao Cai. 29, 467-470.

Yang, Y. C., Lin, H. Y., Su, K. Y., Chen, C. H., Yu, Y. L., Lin, C. C., et al. (2012). Rutin, a flavonoid that is a main component of Saussurea involucrata, attenuates the senescence effect in D-galactose aging mouse model. Evid Based Complement Alternat Med. 2012, 980276. doi: 10.1155/2012/980276

Yi, T., Lo, H., Zhao, Z., Yu, Z., Yang, Z., and Chen, H. (2012). Comparison of the chemical composition and pharmacological effects of the aqueous and ethanolic extracts from a Tibetan "Snow Lotus" (Saussurea laniceps) herb. Molecules. 17, 7183-7194. doi: 10.3390/molecules 17067183

Yi, T., Zhao, Z. Z., Yu, Z. L., and Chen, H. B. (2010). Comparison of the antiinflamatory and anti-nociceptive effects of three medical plants known as "Snow Lotus" herb in traditional Uighur and Tibetan medicines. J. Ethnopharmacol. 128, 405-411. doi: 10.1016/j.jep.2010.01.037

Yi, T., Zhu, L., Zhu, G. Y., Tang, Y. N., Xu, J., Fan, J. Y., et al. (2016). HSCCC-based strategy for preparative separation of in vivo metabolites after administration of an herbal medicine: Saussurea laniceps, a case study. Sci. Rep. 6, 33036. doi: 10.1038/srep33036

Yishakejiang, M., Abudureyimu, K., and Abulake, R. (2005). China medical encyclopedia-Uyghur medicine volume, first ed (Shanghai: Shanghai Science and Technology Press), pp: 7.

Yu, C. Y., Su, K. Y., Lee, P. L., Jhan, J. Y., Tsao, P. H., Chan, D. C., et al. (2013). Potential therapeutic role of hispidulin in gastric cancer through induction of apoptosis via NAG-1 signaling. Evid Based Complement Alternat Med. 2013, 518301. doi: 10.1155/2013/518301

Zhai, K. F., Wang, C., Gao, G. Z., Cao, W. G., Xu., L. S., and Xing, J. G. (2009). Advances in study on Saussurea involucrate. Hubei Agric. Science. 48, 2869-2873.
Zhao, C., Shao, Q. J., Ma, Z. Q., Li, B., and Zhao, X. J. (2016a). Physical and chemical characterizations of corn stalk resulting from hydrogen peroxide presoaking prior to ammonia fiber expansion pretreatment. Ind. Crop Prod. 83, 86-93. doi: 10.1016/j.indcrop.2015.12.018

Zhao, Y., Cai, L., Sui, Q., Lin, F., Jiang, W., Chen, J., et al. (2016b). Facile synthesis of acacetin and its derivatives. Bioorg Med. Chem. Lett. 26, 3577-3580. doi: 10.1016/j.bmcl.2016.06.018

Zhao, C., Cao, Y., Ma, Z. Q., and Shao, Q. J. (2017a). Optimization of liquid ammonia pretreatment conditions for maximizing sugar release from giant reed (Arundo donax L.). Biomass Bioenerg. 98, 61-69. doi: 10.1016/ j.biombioe.2017.01.001

Zhao, C., Qiao, X. L., Cao, Y., and Shao, Q. J. (2017b). Application of hydrogen peroxide presoaking prior to ammonia fiber expansion pretreatment of energy crops. Fuel. 205, 184-191. doi: 10.1016/j.fuel.2017.05.073

Zhao, X. M. (1963). Supplement to compendium of Materia Medica (Beijing: People's Medical Publishing House), 249-251.

Zhou, R., Wang, Z., and Ma, C. (2014). Hispidulin exerts anti-osteoporotic activity in ovariectomized mice via activating AMPK signaling pathway. Cell Biochem. Biophys. 69, 311-317. doi: 10.1007/s12013-013-9800-8

Conflict of Interest: The authors declare that the research was conducted in the absence of any commercial or financial relationships that could be construed as a potential conflict of interest.

Copyright (c) 2020 Gong, Huang, Yang, Qi, Han, Zheng, He, Chan, Tsim and Dong This is an open-access article distributed under the terms of the Creative Commons Attribution License (CC BY). The use, distribution or reproduction in other forums is permitted, provided the original author(s) and the copyright owner(s) are credited and that the original publication in this journal is cited, in accordance with accepted academic practice. No use, distribution or reproduction is permitted which does not comply with these terms. 